\title{
Ninety-five years of observed disturbance-based tree mortality modeled with climate-sensitive accelerated failure time models
}

\author{
Janet Maringer ${ }^{1,2}\left(\mathbb{D} \cdot\right.$ Anne-Sophie Stelzer $^{1} \mathbb{D} \cdot$ Carola Paul $^{3} \cdot$ Axel T. Albrecht $^{1}$ (i)
}

Received: 3 March 2019 / Revised: 20 September 2020 / Accepted: 15 October 2020 / Published online: 16 November 2020

(c) The Author(s) 2020

\begin{abstract}
Modeling disturbance-based tree mortality is becoming increasingly important in the discussion of how to adapt forests to climate change and to preserve their ecosystem services and mitigate the risk of economic losses. In this study, we fitted species-specific interval-censored Accelerated Failure Time models for five major tree species to derive the influence of climate, soil, silvicultural measures, stand and tree characteristics on survival times. We coded all disturbance-based mortality causes as events and analyzed 473,501 individual trees distributed across 2248 long-term (1929-2014) forest growth and yield plots in southwestern Germany. We observed different survival probabilities among tree species with Douglas-fir having the lowest survival probability at age 100 years, followed by Norway spruce and Silver fir. Contrastingly, beech and oak had survival probabilities above 0.98 at age 100 years. Most important factor influencing these survival times was climate. Higher summer temperature shortens the survival time of beech, Silver fir and oak, while Norway spruce suffers more from warmer and wetter winters. Beside climatic factors, base saturation showed a significant positive relationship to survival time for all investigated tree species, except for Norway spruce, which had shorter survival times with increasing cation exchange capacity of the soil. Additionally, short-term effects of destabilization after thinning were found. In conclusion, favoring broadleaved tree species, avoiding heavy thinning in older stands and limiting tree age reduce the probability of disturbance-based tree mortality. However, some of the effects found that cause-unspecific mortality modeling has limited potential to describe the mortality-climate change relation.
\end{abstract}

Keywords Survival analysis $\cdot$ Tree mortality $\cdot$ Disturbances $\cdot$ Climate warming

\section{Introduction}

Natural tree mortality resulting from vitality losses caused by irregular (e.g., disturbances) or regular (e.g., self-thinning, senescence) mortality is one of the most important

Communicated by Arne Nothdurft.

Electronic supplementary material The online version of this article (https://doi.org/10.1007/s10342-020-01328-x) contains supplementary material, which is available to authorized users.

Janet Maringer

janet.maringer@wsl.ch

Anne-Sophie Stelzer

Anne-Sophie.Stelzer@Forst.bwl.de

Carola Paul

carola.paul@uni-goettingen.de

Axel T. Albrecht

axel.albrecht@forst.bwl.de ecological processes in forests (Adame et al. 2010). Regular mortality, also known as self-thinning, occurs due to competition for space, light, water and nutrients (Jutras et al. 2003). Irregular tree mortality is the response to climatic extremes or disturbances that occur with varying frequencies and intensities (Bigler et al. 2006; Zimmermann et al. 2009). Thereby, climate-related abiotic and biotic disturbance agents are expected to alter in magnitude and intensity under future climate change causing augmented tree mortality (Seidl et al. 2017). This will cause feedback reactions in

1 Forest Research Institute Baden-Wuerttemberg, Rehlingstr. 6d, 79100 Freiburg, Germany

2 Swiss Federal Institute for Forest, Snow and Landscape Research WSL, Insubric Ecosystems, A Ramél 18, 6593 Cadenazzo, Switzerland

3 Department of Forest Economics and Sustainable Land-use Planning, Faculty of Forest Sciences and Forest Ecology, University of Göttingen, Göttingen, Germany 
forest structures and communities as well as their ecosystem services and functions (see Anderegg et al. 2012 for review). Therefore, a good understanding of forces driving disturbance-induced tree mortality is important for policymakers and forest managers responsible for implementing adaptive measures to preserve multifunctional forest services and mitigating the risk of economic losses (Hennon et al. 2012; Thapa and Burkhart 2015).

A variety of approaches has been used to describe and model tree mortality at different scales, ranging from global (Allen et al. 2015) to landscape (Breshears et al. 2005; Neumann et al. 2017), to stand (Fortin et al. 2008; Thapa and Burkhart 2015) or individual tree level (Eid and Tuhus 2001; Boeck et al. 2014). All approaches faced the problem of lacking detailed spatial and/or temporal data on tree survival. Tree-ring samples, e.g., have a high temporal resolution but assess only a limited number of species and samples (Kane and Kolb 2014). Inventory data contain much larger sample sizes over a widespread area, but have usually lower temporal resolutions (Staupendahl and Zucchini 2011; Neumann et al. 2017). Nevertheless, they often provide a broad range of silvicultural treatments, site conditions, forest structures and tree characteristics, while the reasons for tree mortality are often insufficiently documented.

The commonly used statistical approach to model tree mortality is logistic regression analysis (e.g., Fernández 2008). Logistic regressions base on a dichotomous response variable modeled over uniform time intervals, which is often not the case for inventory data (Boeck et al. 2014; Hülsmann et al. 2016). Data unification over a defined period merges individuals who experienced the event of interest at different time points within the study period, which may eliminate meaningful variation in mortality patterns (Singer and Willett 2003). Another important aspect is that individuals with unknown event time, i.e., those who do not experience the event during the observation period, have to be censored. Censored observation data call for survival models such as the nonparametric Kaplan-Meier estimator (Kaplan and Meier 1958), the semi-parametric Cox model (Cox 1995) and parametric models (e.g., Accelerated Failure Time Model). Parametric models have the advantage that they are based on a distribution and the effect of predictors is estimated in absolute numbers (e.g., years). Originally developed for medical studies, they are currently becoming popular in forest science (Staupendahl and Zucchini 2011; Neuner et al. 2014; Neumann et al. 2017). So far, only timeindependent variables have been used in survival models, but this generalization might be over-simplifying.

Therefore, we used an innovative approach to detect factors influencing disturbance-based tree mortality by using Accelerated Failure Time Models with time-dependent variables on a long-term (1920-2014) inventory data set. The originality of this study lies in the fact that we investigated the role of time-varying variables concerning forest stand, tree characteristic and climate factors for particular inventory intervals using individual-based species-specific models for European beech (Fagus sylvatica), Douglas-fir (Pseudotsuga menziesii), Norway spruce (Picea abies), Silver fir (Abies alba), Sessile oak (Quercus petraea) and Pedunculate oak $(Q$. robur). The research questions were: (1) Are species-specific mortality trends distinguishable? (2) Did the rates of disturbance-based mortality change over the observation periods? (3) How strong is the relative impact of climatic variables compared with other explanatory variables? (4) Are trends in mortality correlated with changing climatic and environmental conditions, all other factors being constant? (5) Are the climate-dependent mortality trends similar among tree species?

\section{Materials and methods}

\section{Study area and data collection}

The study region, Baden-Wuerttemberg, is the southwestern located federal state of Germany. Here, the Forest Research Institute of Baden-Wuerttemberg established permanent experimental research plots as early as 1872 distributed across the entire federal state (see Fig. 1). They were originally designed to study growth and yield in response to differing silvicultural treatments.

The experimental research plots range in size between 0.1 and $1 \mathrm{ha}$, averaging to the most common size of 0.25 ha. They are both located irregularly in the state and managed using different silvicultural treatments depending on the protocol of each experiment (Dănescu et al. 2016). The plots were managed and investigated for varying periods ranging from one to 95 years with a mean observation length of 34 years. Trees on the research plots were measured every 4 years on average. Standardized documentation of the mortality reason (cause of removal) started around 1920, which constrained us to discard earlier years. Since climate variables are monthly reported until 2014, our final data refer to the period 1920-2014. This leads to a total number of 2,100,016 individual tree observations, comprising Norway spruce (40\%), European beech (15\%), Douglas-fir (15\%), Silver fir (12\%), Sessile oak and Pedunculate oak (both oak species together 5.5\%). The remaining $12.5 \%$ of the data concerns other tree species not considered here. Within each plot, the diameter to breast height (at $1.3 \mathrm{~m}$ height, $\mathrm{DBH}$ ) of all trees with $\mathrm{DBH} \geq 7 \mathrm{~cm}$ was measured to the nearest millimeter on two perpendicular directions. Tree height was measured on random subsamples of 30 trees per species distributed over the whole DBH range and estimated based on dendrometric diameter height equations (Ehring et al. 1999) for the remaining individuals. Mean age 


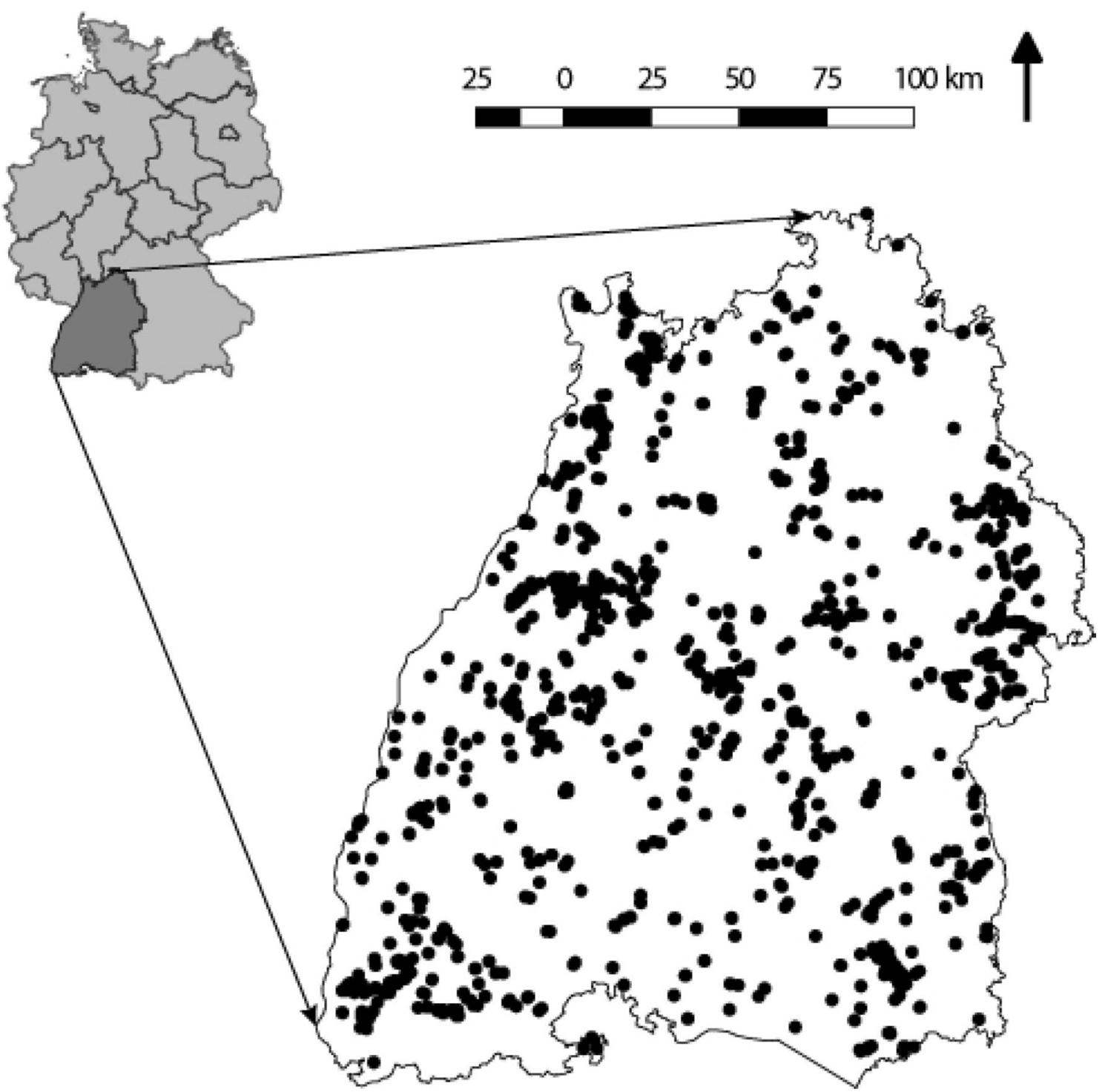

Fig. 1 The Federal state of Baden-Wuerttemberg (Germany) with the location of the permanent research plots used in this study

was available as stand-level information (see list of variables and abbreviations in Table 2).

According to the respective treatment designs, silvicultural approaches on the experimental growth and yield plots consisted of selective cutting, thinning, harvest and regeneration cuts that were performed in coincidence with the respective data measurements. Since these scheduled removals were not caused by the mortality agents of interest in our study, trees removed by experimental thinning or harvest were classified as censored (i.e., not marked as events; Staupendahl 2011; Neuner et al. 2014).

\section{Data preparation}

Classification of trees as disturbance-based mortality events

During field measurements, the tree status (living; non-existing) and the cause for no longer existing trees are attributed to each individual (Table 1). Trees experiencing mortality due to undifferentiated salvage cutting, wind-throw, snowdamage, insect calamities or fungi were classified as a failure (event $=1$ ). Trees surviving until the end of the observation 
Table 1 Cause of removal and tree status (censored/failure)

Status

Censored

(event $=0) /$

Failure

(event $=1)$

Existing and living

0

Non-existing due to experimental thinning or harvest

Non-existing due to undifferentiated salvage cutting

Existing but dead due to wind-throw

Existing but dead due to snow-break

Existing but dead due to insects

Existing but dead due to fungi

Existing but dead $\left(b^{\circ}{ }_{j} \geq b^{\circ}\right)$

Existing but dead $\left(\mathrm{b}^{\circ}{ }_{\mathrm{j}}<\mathrm{b}^{\circ}\right.$ and relDBHRank $\left.\geq 0.5\right)$

Non-existing due to special investigation

Damage caused by game

Maintenance

Non-existing due to unknown reasons

$b^{\circ}$ : the ratio between the basal area of a stand $\left(b^{\circ}\right)$ and the basal area derived from the yield table $\left(\mathrm{b}^{\circ}\right)$; relDBHRank: the ratio between the rank of a tree (based on the DBH sorted in ascending order) and the rank of the largest diameter tree within a stand

period or experiencing mortality through scheduled harvest, special investigation, browsing by game, accidents by maintenance measures or unknown reasons were classified as censored (event $=0$ ). Trees that died due to competition in the self-thinning stage were defined as censored since density-based mortality was not the event of interest in our study. This information was reconstructed by extracting trees with unspecified death cause in densely packed stands that are stands with basal areas greater than the average reported in the corresponding yield tables $\left(\mathrm{b}^{\circ}{ }_{\mathrm{j}} \geq \mathrm{b}^{\circ}\right.$; see Table 1; MLR 1993). In stands of medium density $\left(b^{\circ}{ }_{j}<b^{\circ}\right)$, on the contrary, trees of the dominant or codominant stand strata (relative diameter rank $\geq 0.5$; Table 1 ) with unknown causes of removal were classified as events.

\section{Tree characteristics}

The slenderness coefficient (ratio of height to diameter; RatioHeightDBH), the relative DBH (relDBHRank) and tree height (relHeightRank) were considered as possible alternatives to express the impact of a tree's competitive position. Additionally, the basal area of larger trees (BAL) and its relative counterpart (relBAL) were calculated as indicators for one-sided competition (Wykoff et al. 1982).

\section{Stand structure and diversity}

We calculated the Shannon and Evenness indices (Shannon and Weaver 1949) for each stand as proxies for stand mixture and structure, which relate to the potential forest resistance against biotic agents (Griess and Knoke 2011; Bauhus et al. 2017). We used Shannon's Function $H^{\prime}$ and its standardized version Evenness to calculate tree species diversity (Es) and tree diameter diversity (Ed), respectively. $H^{\prime}$ is calculated from the equation $H^{\prime}=-\sum p_{i}\left(\ln p_{i}\right)$ where $p_{i}$ is the ratio between the number of individuals of tree species $i$ and the total number of trees. For Evenness, $H^{\prime}$ is divided by the theoretical maximum (the natural logarithm of the number of species). Similarly, diameter diversity was calculated by replacing the number of species with the number of DBH classes for a stand (DBH classes in $1 \mathrm{~cm}$ units rounded to the decimal place) as described in Dănescu et al. (2016).

Basal area per hectare (BA) was calculated as indices for two-sided measured (Bravo and Montero 2001). We calculated two thinning indices to consider possible short-term effects on mortality of the remaining trees. First, we calculated the ratio between removed basal area and stand basal area prior to the respective intervention (RelRemoval) as proxy for thinning severity and second the mean DBH of removed trees relative to the quadratic mean $\mathrm{DBH}$ of the entire stand (RelDBHRemoval) to characterize if dominant (greater values) or suppressed trees (smaller values) were predominantly removed.

\section{Site characteristics}

Variables on site characteristics were obtained from the digital terrain model (resolution $1 \mathrm{~m}$ ) and forest stand location map of Baden-Wuerttemberg (Geobasisdaten 2018). We used the indicators slope, aspect and elevation (ELE) to assess topographical parameters influencing tree mortality. Soil conditions were characterized using usable water retention (NFK) and cation exchange capacity (KAK) from the soil map of Baden-Wuerttemberg at a scale of 1:50,000 (Landesamt für Geologie, Rohstoffe und Bergbau [LGRB]). Additionally, we described soil conditions by using the base saturation (\%o) in 10-30 cm depth (base) and the mean rock content (\%o; rock; Hartmann et al. 2016). All variables were obtained from the plot coordinates and digital maps using QuantumGIS $^{\circledR}$, version 2.18 IS (Quantum GIS Development Team 2017).

\section{Climate variables}

Precipitation and temperature are known to influence tree mortality (Lines et al. 2010; Adams et al. 2010). We used spatially interpolated temperature and precipitation data with a monthly resolution (Deutscher Wetterdienst (DWD) Climate Data Center 2018a, c) to calculate the thirty-years average of both annual temperature ( $\left.T_{\text {mean }}\right)$ and annual precipitation sum $\left(P_{\text {sum }}\right)$. The climatic values were calculated for the specific geographic location of each plot and repeated 
Table 2 Species-specific tree characteristics and variables used in the models for Norway spruce, European beech, Douglas-fir, Silver fir, Sessile oak and Pedunculate oak separately listed for: number of trees $\left(N_{\text {Trees }}\right)$, number of observations $\left(N_{\text {Observation }}\right)$, percentage of died trees (Dead), mean diameter at breast height (DBH) and height, stand age, relative removed basal area (RelRemoval), basal area ( $\varnothing \mathrm{BA})$, species Evenness (Es), tree diameter Evenness (Ed), slope, aspect, elevation (ELE), base saturation (base), soil rock content (rock) as well as for maximum $\left(T_{\max }\right)$, minimum $\left(T_{\min }\right)$ and mean temperature $\left(T_{\text {mean }}\right)$ and similar for precipitation $(\mathrm{P})$

\begin{tabular}{|c|c|c|c|c|c|c|c|}
\hline & Unit & European beech & Douglas-fir & Norway spruce & Silver fir & $\begin{array}{l}\text { Sessile \& Pedun- } \\
\text { culate oak }\end{array}$ & $\begin{array}{l}\text { Vari- } \\
\text { able used in } \\
\text { models }\end{array}$ \\
\hline \multicolumn{8}{|l|}{ General information } \\
\hline Number of plots & & 815 & 493 & 1188 & 480 & 436 & \\
\hline Remeasured interval & Year & 4.1 & 3.2 & 3.5 & 4.2 & 3.7 & \\
\hline$N_{\text {Trees }}$ & & 84,527 & 84,775 & 211,895 & 60,191 & 32,113 & \\
\hline$N_{\text {Observation }}$ & & 127,756 & 361,718 & 955,707 & 292,190 & 127,756 & \\
\hline Dead & $\%$ & 0.3 & 9.3 & 1.7 & 6.1 & 0.2 & \\
\hline $\begin{array}{l}\varnothing \mathrm{DBH} \\
\text { relDBHRank }\end{array}$ & $\mathrm{cm}$ & 20.3 & 21.6 & 21.5 & 23.5 & 18.8 & $\begin{array}{l}\bullet^{\text {b, sp, dgl, s, o }} \\
\bullet \text { b, sp, dgl, s, o }\end{array}$ \\
\hline $\begin{array}{l}\varnothing \text { height } \\
\text { relHeightRank }\end{array}$ & $\mathrm{m}$ & 19.1 & 18.7 & 19.9 & 18.3 & 15.9 & $\begin{array}{l}\text { - } \\
\text { - } \mathrm{sp}, \mathrm{dgl}, \mathrm{s}, \mathrm{o}\end{array}$ \\
\hline \multicolumn{8}{|c|}{ Variables used in the models } \\
\hline$\varnothing$ age & Year & 81.5 & 32.7 & 57.7 & 80.6 & 60.3 & \\
\hline$\varnothing$ RelRemoval & & 0.05 & 0.06 & 0.04 & 0.05 & 0.06 & $\bullet$ \\
\hline RelDBHRemoval & & & & & & & $\bullet$ sp, dgl \\
\hline$\varnothing \mathrm{BA}$ & $\mathrm{m}^{2} \mathrm{ha}^{-1}$ & 29.84 & 33.1 & 40.8 & 41 & 21.9 & $\bullet^{\mathrm{sp}, \mathrm{o}}$ \\
\hline relBAL & & & & & & & - $^{\mathrm{b}, \mathrm{sp}, \mathrm{dgl}, \mathrm{s}}$ \\
\hline BAL & & & & & & & $\bullet^{\mathrm{b}, \mathrm{sp}, \mathrm{dgl}, \mathrm{s}}$ \\
\hline$\varnothing \mathrm{Es}$ & & 0.35 & 0.06 & 0.13 & 0.42 & 0.35 & $\bullet$ \\
\hline$\varnothing \mathrm{Ed}$ & & 0.92 & 0.9 & 0.91 & 0.93 & 0.88 & $\bullet$ \\
\hline$\emptyset$ slope & & 14.3 & 18.03 & 9.4 & 17.9 & 10.6 & $\bullet$ \\
\hline Aspect & & & & & & & $\bullet$ \\
\hline$\varnothing \mathrm{ELE}$ & $\mathrm{m}$ a.s.l. & 533.7 & 520 & 641 & 668 & 408 & $\bullet^{\mathrm{sp}, \mathrm{dgl}, \mathrm{s}}$ \\
\hline$\varnothing$ base & $\%$ & 422.1 & 231 & 256 & 216 & 243 & - \\
\hline$\varnothing \mathrm{NFK}$ & Vol\% & 2.9 & 2.7 & 3.2 & 2.5 & 3.6 & $\bullet$ \\
\hline$\varnothing \mathrm{KAK}$ & $\mathrm{cmol} / \mathrm{kg}$ & 3.2 & 2.63 & 3.1 & 2.6 & 3.2 & • \\
\hline Rock & $\%$ & 165.5 & 193 & 152 & 179 & 37.8 & • \\
\hline$\varnothing T_{\max }$ & ${ }^{\circ} \mathrm{C}$ & 19.1 & 19.8 & 18.6 & 18.4 & 20.2 & $\bullet$ \\
\hline$\varnothing T_{\min }$ & ${ }^{\circ} \mathrm{C}$ & -5.42 & -4.1 & -5.5 & -5.6 & -4.8 & - \\
\hline$\varnothing T_{\text {mean }}$ & ${ }^{\circ} \mathrm{C}$ & 7.7 & 8.2 & 7.3 & 7.2 & 8.5 & •b, sp, dgl, s, o \\
\hline$\varnothing P_{\max }$ & $\mathrm{mm}$ & 204.3 & 219 & 235 & 279.9 & 185.5 & $\bullet$ \\
\hline$\emptyset P_{\min }$ & $\mathrm{mm}$ & 8.8 & 12.3 & 10.52 & 11.6 & 7.15 & $\bullet$ \\
\hline$\emptyset P_{\text {sum }}$ & $\mathrm{mm}$ & 943 & 1033 & 1042 & 1228 & 861 & $\bullet$ b, sp, dgl, s, o \\
\hline $\mathrm{Am}$ & $\mathrm{cm} /{ }^{\circ} \mathrm{C}$ & 21.5 & 23.5 & 24.7 & 25.8 & 19.8 & $\bullet^{\mathrm{b}, \mathrm{sp}, \mathrm{dgl}, \mathrm{s}, \mathrm{o}}$ \\
\hline
\end{tabular}

Additional variables tested in the model are: (relative) basal area of larger trees (BAL, relBAL), ranked height (relHeightRank) and similar the dbh (relDBHRank), aridity index (Am)

The "•" shows if the variable is used in the model. Superscript indicates whether the variable was excluded from the European beech (b), Douglas-fir (dgl), Norway spruce (sp), Silver fir (s) or oak (o) model due to high correlation (variance inflation factor $\geq 3$ ) with other variables

as a moving average for each plot observation. This means that for an exemplary plot observation in 1987, the values of the preceding 30-year period (1958-1987) were used.

Since tree species react often to alterations in frequency and intensities of climatic extremes (Bigler et al. 2006; Fuhrer et al. 2006; Pulliam 2000; Zimmermann et al. 2009), we calculated mean maximum $\left(T_{\max }\right)$ and mean minimum $\left(T_{\min }\right)$ temperature of the warmest and coldest month, respectively, and equivalently the precipitation sums $\left(P_{\min }, P_{\max }\right)$ (Deutscher Wetterdienst (DWD) Climate Data Center 2018b, d; Vanoni et al. 2016). To consider climatic extremes also for the first observation, we calculated the mentioned parameters for the previous 5 years. Additionally, we calculated the De Martonne (1926) aridity 
index (Am), which is the ratio between the mean precipitation $(\mathrm{cm})$ and the mean temperature $\left({ }^{\circ} \mathrm{C}\right)$ plus ten. A summary of the used variables is provided in Table 2.

\section{Data analysis}

The computations were performed in $\mathrm{R}$ ( $\mathrm{R}$ Development Core Team 2014) using the packages data.table (Dowle et al. 2019) and dplyr (Wickham et al. 2018). Data exploration followed the guidelines of Zuur et al. (2010), which suggest the use of Pearson's correlation coefficient and the variance inflation factor (VIF) to detect collinearity among variables. Variables with a VIF $\geq 3$ were excluded from further analysis.

Annual species-specific mortality rates, $m$, were calculated at the population level per inventory period based on individual tree data (Sheil et al. 1995):

$m=1-\left(N_{t} / N_{0}\right)^{1 / t}$

where $N_{0}$ and $N_{t}$ are tree counts at the beginning and the end of the inventory interval, respectively, with $t$ representing the length of the inventory interval in years. We used the nonparametric Cox and Stuart Trend Test to detect trends in a time series (Cox 1995).

With the aid of the survival package (Therneau 2018), we used the nonparametric Kaplan-Meier (Kaplan and Meier 1958) estimator to detect substantial differences in the observed survival probability among tree species. We further tested differences in survival time using a log-rank test. Stand age, $T$, at the beginning and end of the observation interval together with the coded event $(0 / 1)$ was the focus of the survival analysis. We selected stand age instead of other parameters (e.g., dbh, height) as time variable since age is often used in forest economic simulations and is therefore comparable with other models (Griess and Knoke 2013; Netherer et al. 2015; Paul et al. 2019; Brandl et al. 2020). The nonparametric Kaplan-Meier estimator of the survival function $S(t)$ of $T$ is defined as (Kaplan and Meier 1958):

$S(t)=\prod_{i: t_{(i)} \leq t}\left(1-\frac{d_{i}}{n_{i}}\right)$

where ${ }^{\prime}(0)=1, d_{i}$ is the trees that fail at $t_{(i)}$ and $n_{i}$ represents the total number of subjects at risk at $t_{(i)}$. The Kaplan-Meier estimator was used to give a descriptive overview of a tree's survival probability considering no or one predictor. In addition to displaying survival probability as a function of age, we also graphed it as a function of tree height. This has the advantage of making sites of different fertility more comparable since trees grow more rapidly in height on sites with high fertility.
Subsequently, we assessed factors influencing tree survival time using parametric Accelerated Failure Time models (AFT models), since they can handle censored data and calculate the distribution form of survival time (Zhang 2016). Since the investigated tree species, except Sessile and Pedunculate oak (Eaton et al. 2016), have different ecological niches, we performed species-specific AFT models. In contrast to proportional hazard models, AFT models estimate the baseline survival function. In the case of a survival time $T \geq 0$, the natural logarithm of the survival time, $Y_{j}=\ln \left(T_{j}\right)$, is expressed as a linear function of the covariates (Mills 2011):

$Y_{j}=\ln \left(T_{j}\right)=x_{j}^{\prime} \beta+z_{j}$

with $x_{j}$ representing the vector of covariates for subject $j$, $\beta$ the vector of estimated regression coefficients and $z_{j}$ the error term with density function $f(z)$. The form of $f(z)$ determines the regression model. In our case, $f(z)$ is set to the extreme value density so that we get the Weibull regression model (Mills 2011).

The exponentiated form of $\beta$ is the time ratio. In case $\exp (\beta)$ is greater (less) than one, the covariate indicates a decreased (increased) time to death-in other words shrinking (stretching) the baseline survivor function along the $x$-axis. Since the data are left truncated and interval censored, we used the eha-package developed by Broström (2017). The underlying assumption of interval-censored data is that the hazard is constant within each interval, but can vary across intervals (Mills 2011). Left truncation means that only individual trees whose lifetimes lie within a certain interval (minimum observed stand age to the maximum observed stand age) are considered in the models. Truncation considers the existence and potential mortality events in stands before they entered the survey (age < observed stand age).

Advantages of parametric AFT models include: (1) the distribution of survival time can be estimated, (2) the effects of covariates can be estimated in absolute terms (e.g., years), (3) variation in observation intervals accompanied by timedependent covariates can be considered (Moore 2016) and (4) the full maximum likelihood can be used to estimate parameters (Mills 2011; Zhang 2016). Since the survival time follows a particular distribution, we considered models using the Weibull distribution. The best-fitting distribution was selected based on the comparisons of (1) the modeled distribution with the nonparametric Kaplan-Meier curve, (2) the lowest Akaike Information Criterion (AIC) (Burnham and Anderson 2002) and (3) the maximized log-likelihood.

\section{Model performance and selection}

All models were tree individual based using stand age as time scale. All continuous explanatory variables were $z$-score transformed to facilitate the comparative interpretability of 
the estimated coefficients. As a first step, the potential influence of nominal and ordinal variables on the survival probability of the respective tree species was visualized with a Kaplan-Meier curve. Since continuous variables cannot be presented in a Kaplan-Meier curve, those variables were divided into ranges below and above their median. Variables strongly differing in the Kaplan-Meier curves of the two groups (above/below the median) were prioritized in the first step of AFT model selection (Hosmer et al. 2008). Based on the variable selection procedures as proposed by Glomb (2007), each AFT model was first fitted for single explanatory variables separately to detect significant impacts on survival times. In the second step, significant variables were combined in models until the species-specific model with the lowest AIC and a baseline curve close to the Kaplan-Meier curve were obtained. Finally, we added the non-significant variables of the first step back to confirm or reject the lack of statistical significance. During the variable selection process, we tested interactions among variables. The significance between models was tested by comparing the complex with the nested model using the likelihood ratio test.

The characterization of the model error was analyzed based on a test data set $(30 \%$ of the original data set randomly chosen). The best individual tree model was applied to the training data set, and the predicted survival probability was graphed against observed values (Kaplan-Meier curve). Additionally, models based on the test data set were calculated with the same predictors as those for the training data set to evaluate the magnitude and direction of the coefficients.

\section{Results}

\section{Patterns in tree mortality}

Comparing the observed survival probabilities by using a log-rank test shows that survival rates differed significantly $(p<0.0001)$ among tree species. The nonparametric Kaplan-Meier analysis showed that European beech had the highest survival probability being above 0.9 over the entire observed lifespan of 228 years (see Fig. 2). Similarly high were the values for both oak species, which showed a survival probability of $>0.95$ until the age of 170 . Beyond that age, the survival probability decreased to values between 0.8 and 0.9. Silver fir showed a survival probability similar to European beech and the two oak species until the age of 75 . However, for older trees, the survival probability decreased continuously showing values of 0.94 at age 100 and 0.7 at age 200. Norway spruce showed intermediate probabilities to survive with 0.83 at age 100 years. The survival

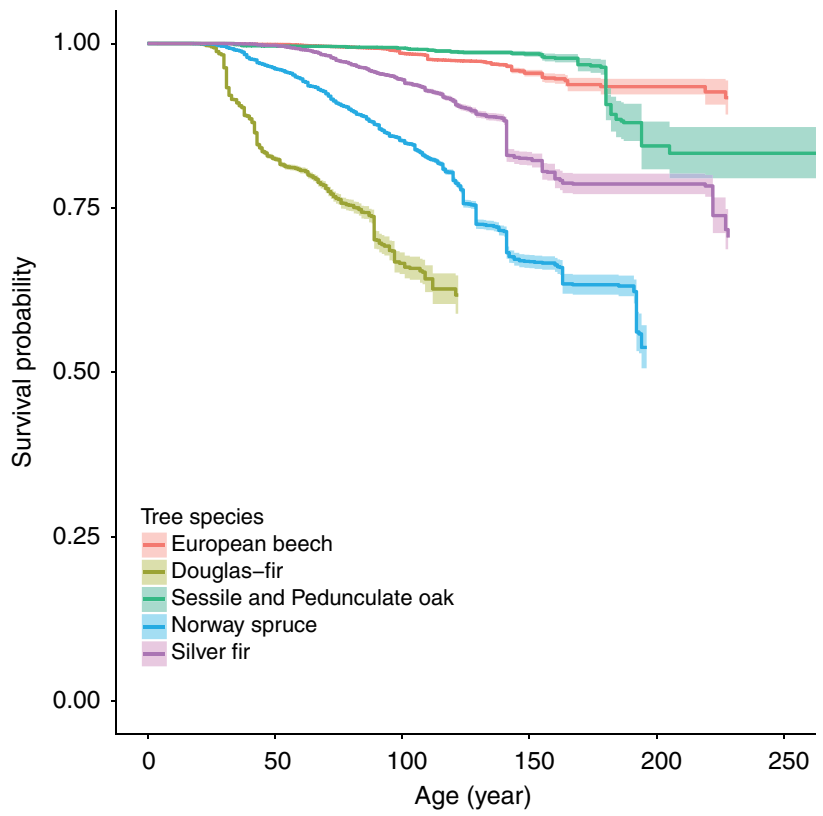

Fig. 2 Kaplan-Meier survival probability with confidence intervals over stand age (years) for European beech, Douglas-fir, Norway spruce, Silver fir, Sessile oak and Pedunculate oak

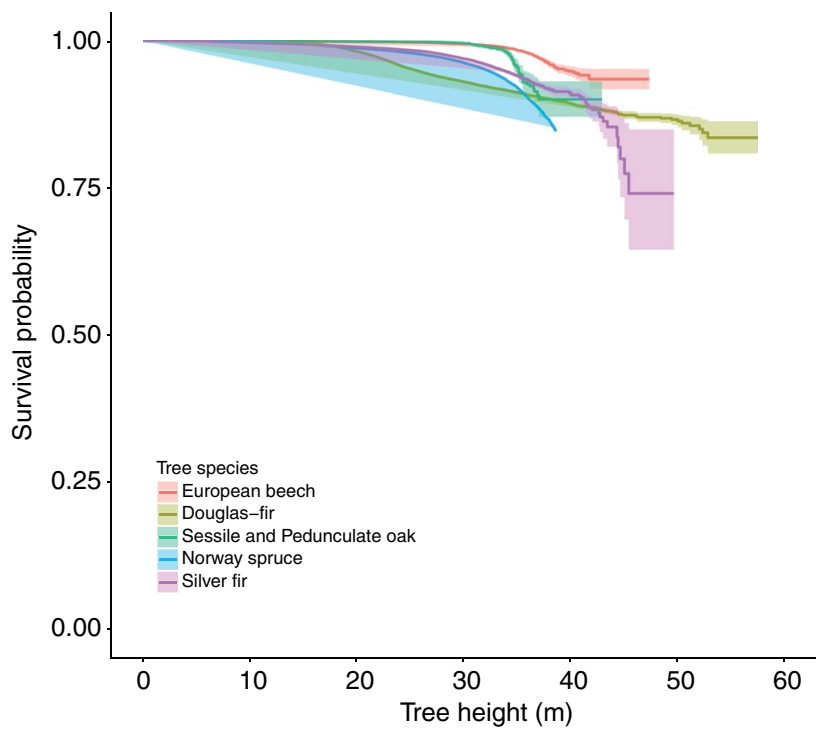

Fig. 3 Kaplan-Meier survival probability with confidence intervals over tree heights (m) for European beech, Douglas-fir, Norway spruce, Silver fir, Sessile oak and Pedunculate oak

probability of Douglas-fir rapidly decreased to 0.63 at the age of 100 years.

The height-depending Kaplan-Meier curves were much more uniform for the different tree species, showing similar patterns for the different tree species, than the age-depending Kaplan-Meier curves. Both European beech and oak showed the highest survival probabilities with values above 0.99 at 
$30 \mathrm{~m}$ height $\left(\mathrm{S}_{\mathrm{H} 30}\right.$ : survival probability at height $30 \mathrm{~m}$, see Fig. 3). Intermediate survival probabilities were found for Norway spruce $\left(S_{\mathrm{H} 30}=0.96\right)$ and Silver fir $\left(S_{\mathrm{H} 30}=0.96\right)$, while the survival probability of Douglas-fir was lowest $\left(\mathrm{S}_{\mathrm{H} 30}=0.93\right)$ at the reference height of $30 \mathrm{~m}$.

\section{Temporal trends in tree mortality}

Besides the overall mortality also the annual mortality rates and the mortality agents for different decades differed among tree species (see Figs. 4 and 5). Wind-throw and snow-damage were the predominant mortality agents for all investigated species. Generally, mortality caused by wind-throw increased since 1990 (Fig. 4). Within the period 1950-1990, snow-damage caused mainly death in
Norway spruce and Silver fir stands, whereas European beech mainly died due to undifferentiated salvage cutting (see Fig. 4).

Across the entire observation period from 1920 to 2014, Douglas-fir showed the highest mean annual mortality rate with $0.5 \%$, followed by Norway spruce with $0.4 \%$. The annual mortality rates for Silver fir, European beech, Sessile oak and Pedunculate oak were $0.22 \%, 0.07 \%$ and $0.06 \%$ (for both oak species), respectively. Results of the Cox and Stuart Trend Test showed that the annual mortality has not significantly changed with time for all tree species (European beech: $\mathrm{p}=0.06$, Norway spruce: $\mathrm{p}=0.37$, Sessile \& Pedunculate oak: $p=0.24$, Silver fir: $p=0.25$, Douglas-fir: $p=0.43$ ).
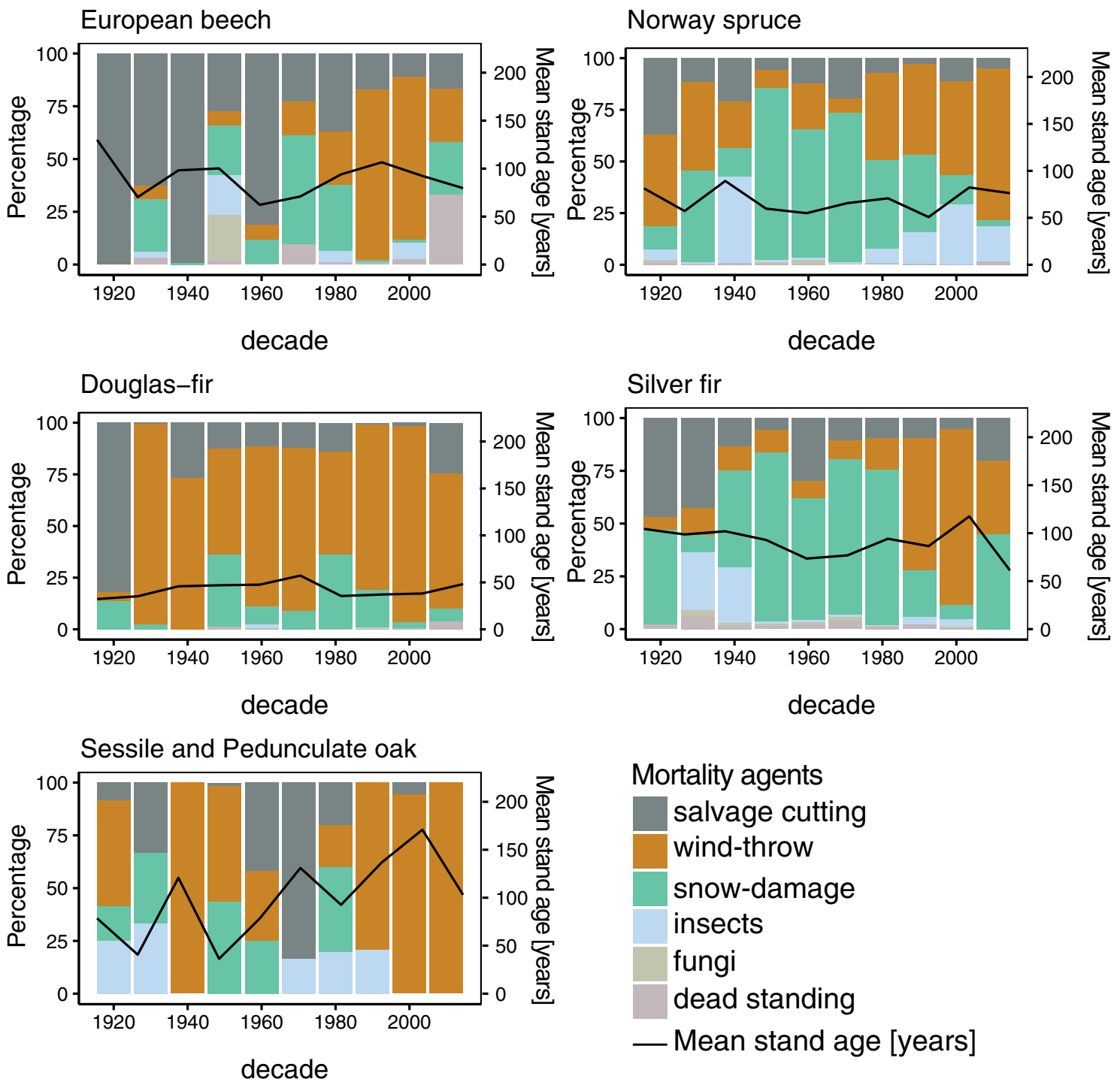

Silver fir

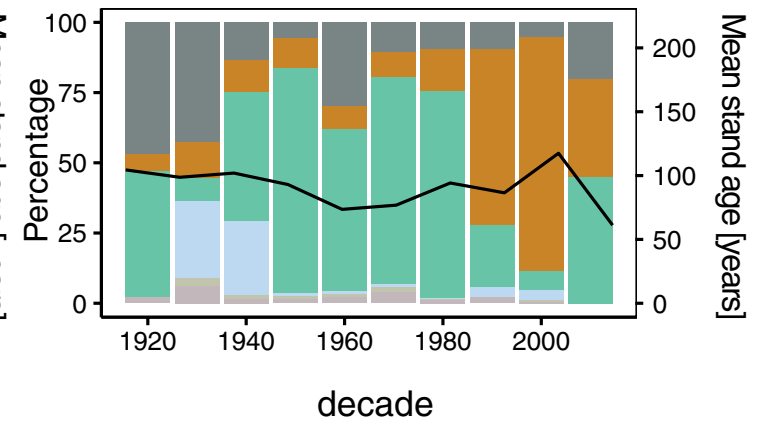

Mortality agents

salvage cutting
wind-throw
snow-damage
insects
fungi
dead standing
_ Mean stand age [years]

Fig. 4 Shares of disturbance-based mortality occurring on the long-term research plots by agents (colors) and species (panels) across calendar time. The solid black line indicates the periodic mean stand age of the plots in the survey 
Fig. 5 Development of the annual disturbance-based mortality rate by tree species on the long-term research plots across the period of investigation

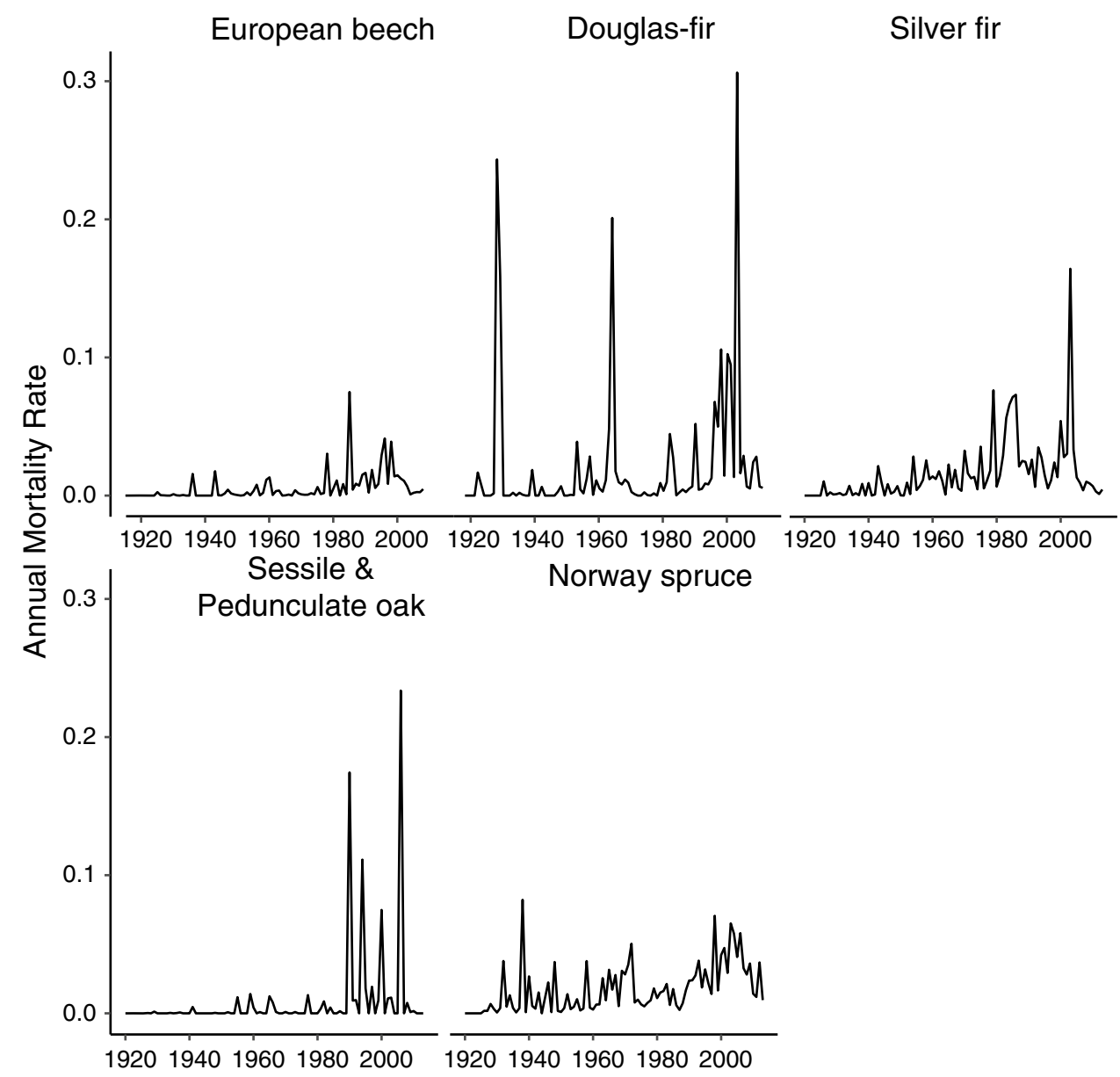

\section{Species-specific mortality models}

Table 3 shows the estimated exponentiated coefficients of the covariates, $\exp (\beta)$, which we integrated into the best species-specific AFT models. Among the five different species-specific AFT models, those including climate, soil and silvicultural parameters provided the lowest AIC representing the best goodness of fit. By holding all variables in the model at their means, the survival probability at age 100 years ranges from 0.99 for European beech, Sessile and Pedunculate oak to 0.75 for Douglas-fir. Silver fir and Norway spruce show intermediate survival probabilities with 0.95 and 0.85 , respectively (see Fig. 6).

\section{The influence of climate parameters}

The climatic variables influenced the survival times of the tree species differently (see Table 3 ). $P_{\min }$ extended the survival time of Douglas-fir by $8 \%$ (coefficient value 0.92). $T_{\max }$ significantly shortened the survival time of European beech by $20 \%$ (coefficient value 1.2), both oak species by $21 \%$ and Silver fir by $13 \%$. In case of European beech and Silver fir, the 0.05 - and 0.95 -percentile range for
$T_{\max }$ corresponded to temperatures from 16.0 to $21.0^{\circ} \mathrm{C}$. The corresponding $T_{\max }$ dimension for the two oak species ranged from 18.4 to $21.9{ }^{\circ} \mathrm{C}$ (see Fig. 7). An opposite effect was detected for Norway spruce, which seems to suffer from warmer winter temperatures $\left(T_{\min }\right.$ coefficient $1.37)$ and increasing maximum precipitation $\left(P_{\max }\right.$ coefficient 1.21).

\section{The influence of soil characteristics}

Besides climatic factors, also soil parameters showed a significant relationship to survival time for all investigated tree species. Norway spruce displayed shorter survival times by increasing cation exchange capacity of the soils (see Fig. 8 and Table 3). Higher base saturation extended the survival times for all tree species, except for Norway spruce, ranging from $26 \%$ for the two oak species (coefficient value 0.74, see Table 3) over 7\% for Douglasfir (coefficient value 0.93 , see Table 3 ) to $4 \%$ for both, European beech and Silver fir (coefficient value 0.96, see Table 3). 
Table 3 Exponentiated coefficients $[\exp (ß)]$ of the species-specific AFT models

\begin{tabular}{|c|c|c|c|c|c|}
\hline Models & $\begin{array}{l}\text { European beech } \\
\exp (ß)\end{array}$ & $\begin{array}{l}\text { Douglas-fir } \\
\exp (\beta)\end{array}$ & $\begin{array}{l}\text { Norway spruce } \\
\exp (ß)\end{array}$ & $\begin{array}{l}\text { Silver fir } \\
\exp (ß)\end{array}$ & $\begin{array}{l}\text { Sessile \& Pedunculate oak } \\
\exp (B)\end{array}$ \\
\hline \multicolumn{6}{|l|}{ Climate variables } \\
\hline$T_{\max }$ & $1.20[ \pm 0.01]^{* * *}$ & - & - & $1.1[ \pm 0.01]^{* * *}$ & $1.21[ \pm 0.04]^{* * *}$ \\
\hline$T_{\min }$ & $0.95[ \pm 0.02]^{*}$ & - & $1.37[ \pm 0.01]^{* * *}$ & - & - \\
\hline$P_{\max }$ & $1.97[ \pm 0.01]^{* * *}$ & - & $1.21[ \pm 0.01]^{* * *}$ & $1.02[ \pm 0.01]^{\text {n.s. }}$ & - \\
\hline$P_{\min }$ & - & $0.92[ \pm 0.02]^{* * *}$ & - & - & - \\
\hline$P_{\max } T_{\min }$ & $1.02[ \pm 0.01]^{*}$ & - & $0.84[ \pm 0.004]^{* * *}$ & - & - \\
\hline \multicolumn{6}{|l|}{ Soil parameters } \\
\hline Base & $0.96[ \pm 0.15]^{* *}$ & $0.93[ \pm 0.01]^{* * *}$ & - & $0.96[ \pm 0.01]^{* *}$ & $0.74[ \pm 0.08]^{* * *}$ \\
\hline KAK & - & - & $1.2[ \pm 0.005]^{* * *}$ & - & - \\
\hline NFK & - & $0.94[ \pm 0.01]^{* * *}$ & - & - & - \\
\hline Rock & - & - & - & - & $0.75[ \pm 0.06]^{* * *}$ \\
\hline \multicolumn{6}{|c|}{ Silvicultural measures } \\
\hline RelRemoval & - & - & $1.12[ \pm 0.002]^{* * *}$ & $1.26[ \pm 0.01]^{* * *}$ & $1.45[ \pm 0.03]^{* * *}$ \\
\hline RelDBHRemoval & $1.27[ \pm 0.00]^{* * *}$ & - & - & - & - \\
\hline \multicolumn{6}{|l|}{ Tree characteristic } \\
\hline Height & - & - & - & $0.87[ \pm 0.01]^{* * *}$ & $0.83[ \pm 0.04]^{* * *}$ \\
\hline relHeightRank & $0.87[ \pm 0.01]^{* * *}$ & - & - & - & - \\
\hline \multicolumn{6}{|c|}{ Stand characteristic } \\
\hline BA & - & $1.07[ \pm 0.12]^{* * *}$ & - & - & $1.39[ \pm 0.04]^{* * *}$ \\
\hline Es & - & - & $0.94[ \pm 0.01]^{* * *}$ & - & - \\
\hline Ed & - & $1.48[ \pm 0.02]^{* * *}$ & - & - & - \\
\hline \multicolumn{6}{|c|}{ Baseline parameters } \\
\hline $\log ($ scale $)$ & $5.66[ \pm 0.03]$ & $5.14[ \pm 0.03]$ & $5.29[ \pm 0.008]$ & $5.66[ \pm 0.03]$ & $6.12[ \pm 0.14]$ \\
\hline $\log ($ shape $)$ & $1.49[ \pm 0.03]$ & $0.84[ \pm 0.02]$ & $1.009[ \pm 0.009]$ & $0.44[ \pm 0.02]$ & $0.93[ \pm 0.07]$ \\
\hline
\end{tabular}

Exponentiated coefficients below (above) one denote an extension (deceleration) of survival time. Standard errors are shown in square brackets with the significance levels $(* * * \leq 0.001 ; * * p \leq 0.01 ; * p \leq 0.05$; n.s., not significant). $\log ($ scale) and $\log ($ shape) are the scale and shape parameters of the Weibull distribution, respectively

Interaction term

Fig. 6 Comparison between the modeled baseline survival probability (gray line) and the observed Kaplan-Meier curve (red line) for all species-specific models
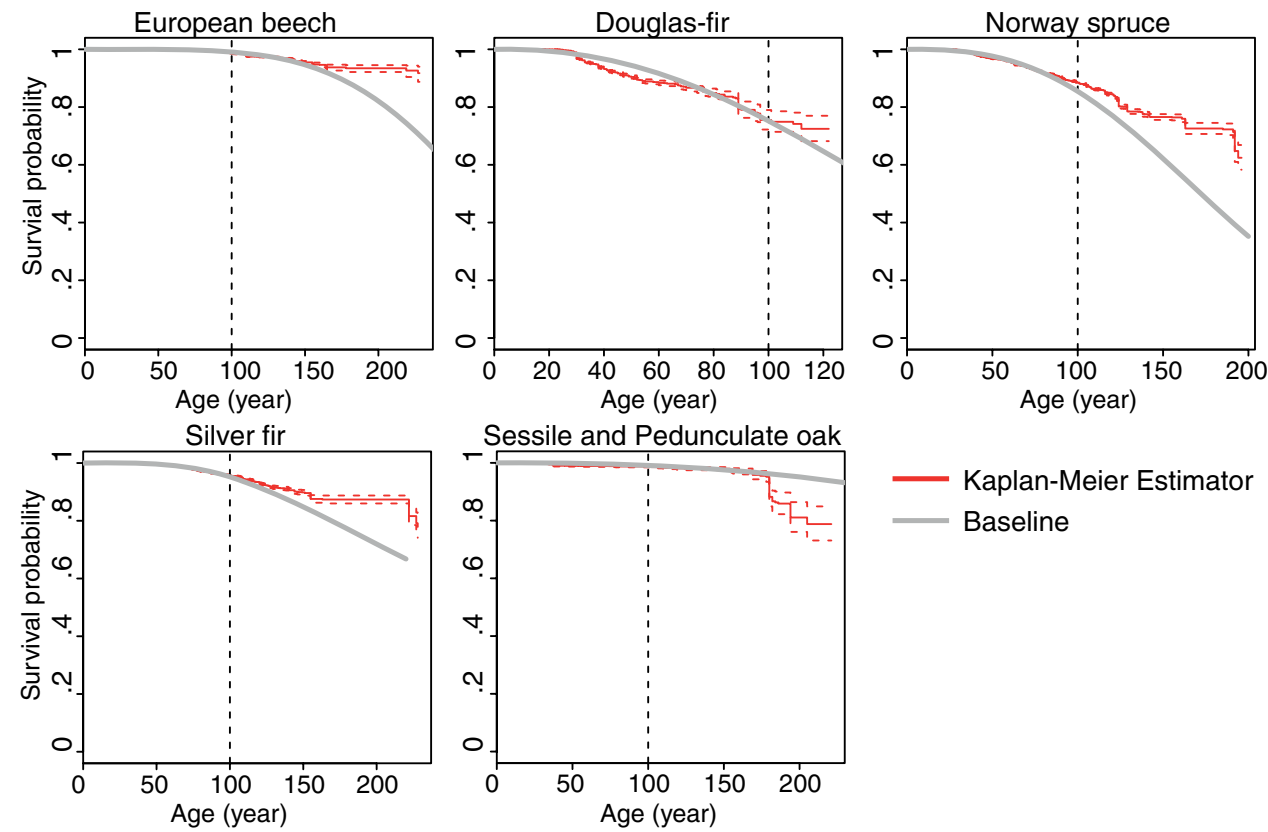

\section{Baseline}



climatic variables on tree surbeech, Douglas-fir, Norway spruce, Silver fir, Sessile oak and Pedunculate oak. The solid line shows the 0.05-percentile and the dashed the 0.95 -percentile for all climate variables
Fig. 7 Modeled influence of vival probabilities for European
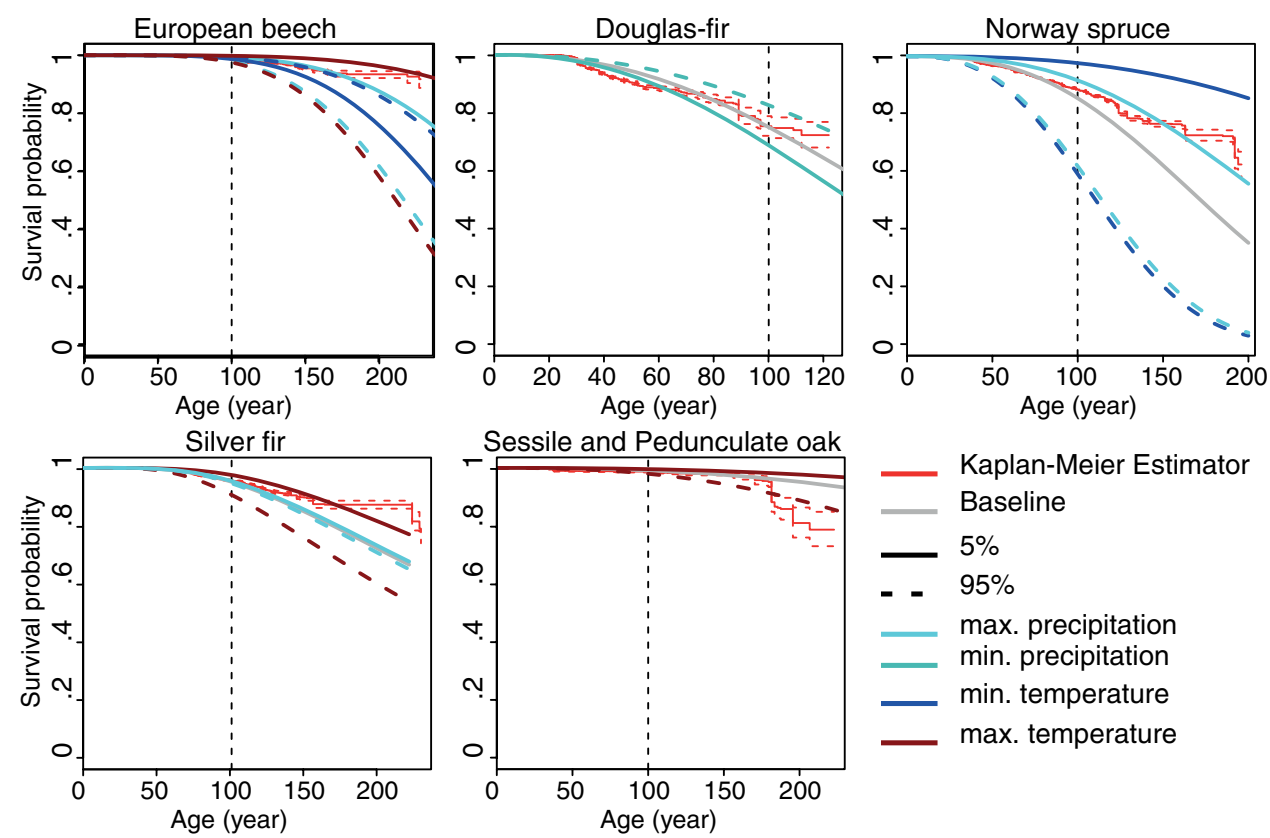

Fig. 8 Modeled influence of soil variables (base saturation, rock content, water storage capacity) on tree survival probabilities for European beech, Douglasfir, Norway spruce, Silver fir, Sessile oak and Pedunculate oak. The solid line shows the 0.05 -percentile; dashed line shows the 0.95 -percentile
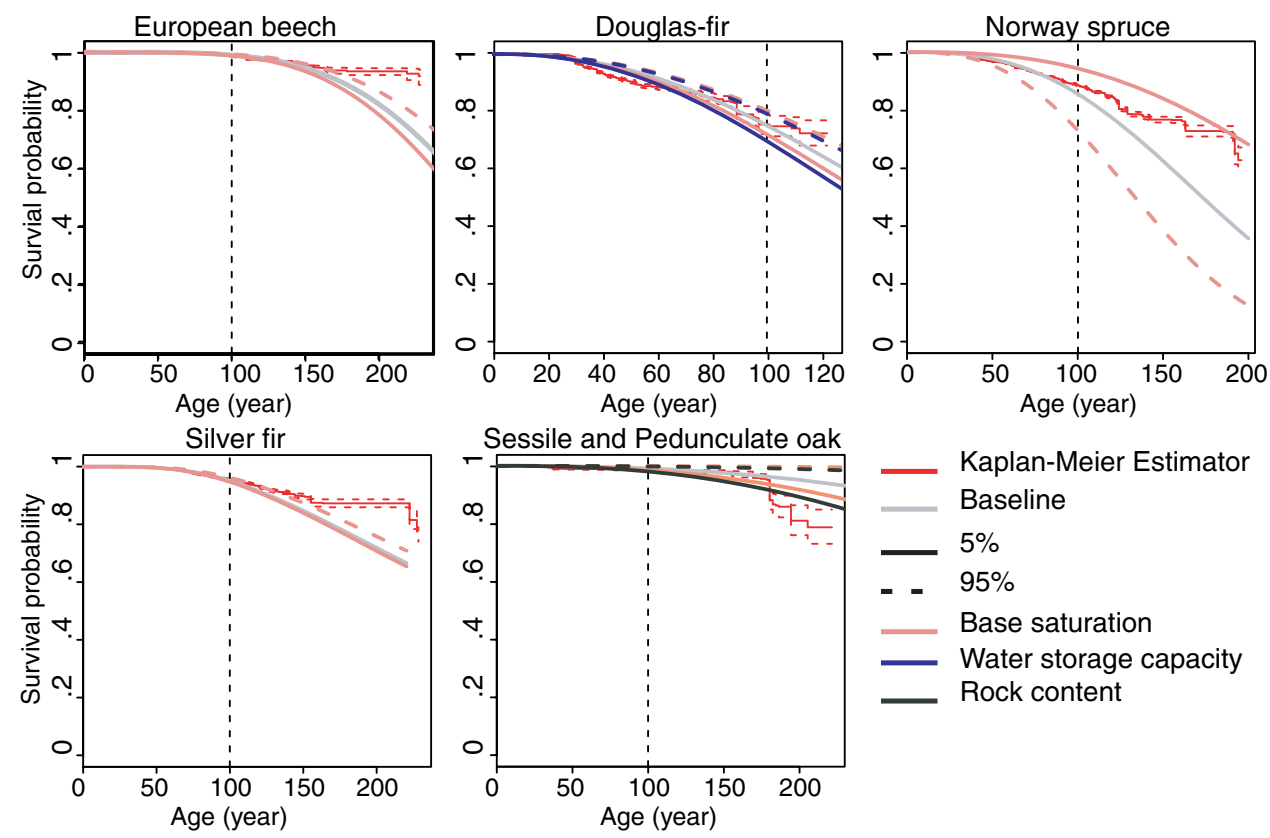

\section{The influence of silvicultural treatments}

The ratios between the removed basal area and the stand basal area to the respective inventory (RelRemoval) were significantly related to the survival times for all investigated tree species, except for Douglas-fir. With increasing removed basal area, the survival times shortened by $45 \%$ for oak (coefficient value 1.45, see Table 3), 26\% for Silver fir (coefficient value 1.26) and $12 \%$ for Norway spruce (coefficient value 1.12). For European beech, the mean DBH of the removed trees relative to the quadratic mean DBH of the entire stand (RelDBHRemoval) was significant, meaning that the survival times shortened for the remaining trees in case the dominant trees were removed (coefficient value 1.27 , see Table 3 ).

\section{The influence of tree and stand characteristics}

Both tree and stand characteristics were not ubiquitously significant among species-specific models. Height was significant in the Silver fir (coefficient value 0.87, see Table 3) and oak models (coefficient value 0.83 , see Table 3 ), indicating 
extended survival times for tall trees. In the case of European beech, the relative height was significant indicating an extended survival time for trees taller than the mean stand height (coefficient value 0.86, see Table 3).

Basal area was significant in the Douglas-fir (coefficient value 1.07, see Table 3 ) and oak models (coefficient value 1.39 , see Table 3), reducing the survival time with increasing basal area. The species evenness index (Es) was significant in the Norway spruce model (coefficient value 0.94 , see Table 3) showing an extension of survival time in mixed stands, while the diversity of tree diameters had an opposite effect in the Douglas-fir model (coefficient value 1.48, see Table 3).

\section{Discussion}

\section{Annual mortality rates and disturbance agents}

In this study, we assessed the survival times and the driving factors of five dominant tree species in southern Germany's forests over a period of more than 100 years. Despite the limitations, which consequently limit the interpretation (discussed below), some clear patterns emerged: Annual mortality rates varied considerably across species ranging between $0.06 \%$ for oak and $0.22 \%$ for Silver fir. While the annual mortality rates equal those found in Swiss forests (Etzold et al. 2019), we could not detect any considerable changes across time in the annual mortality rates as had been found in the Swiss study. This may result from the fact that we have not made any specific distinctions, e.g., by ecoregions or elevation (Etzold et al. 2019).

However, our results show that disturbance agents differed among decadal periods. Storm damage, e.g., increased for all species toward the end of the twentieth century, which can be related to the exceptional storms in 1990 and 1999 (Schelhaas et al. 2003). The mortality regime of the first half of the twentieth century was much more dominated by the occurrence of snow-damage, especially for Norway spruce and Silver fir.

\section{Species-specific survival times}

Our results further show that the observed age-dependent survival probability differed among species. The highest age-dependent survival probabilities were observed for the long-lived species European beech, Sessile oak, Pedunculate oak and Silver fir. Comparable survival probabilities at the age of 100 years were obtained by Neumann et al. (2017) and Neuner et al. (2014) for Norway spruce and European beech, whereas others report lower survival probabilities for Norway spruce at corresponding ages (Staupendahl and Zucchini 2011; Griess et al. 2012; Brandl et al. 2020). This difference might result from (1) the spatial and temporal differences in the underlying data, (2) by using different approaches for calculating the Kaplan-Meier survival curves (one observation period per tree versus multiple observations), (3) from the study design (crown condition data) or (4) from generally differing environmental conditions.

Surprisingly, the non-native Douglas-fir had the lowest observed survival probability $\left(S_{(100)}=0.75\right)$ in our study area. This goes in line with observations for entire Europe (Brandl et al. 2020) but contradicts regionally specific models (Staupendahl and Zucchini 2011). Although the species is known as a long-lived, shade-intolerant or semi-tolerant tree in its natural distribution area in North America (Da Ronch et al. 2016), the observed high mortality rate in the study area may result from the species' vulnerability to wind-throw outside its natural range (Albrecht et al. 2013). Douglas-fir's mortality occurred especially in young stands. We hypothesize that there may be unstable phases during the development of younger and mid-aged stands (height 20-30 m, ages 40-60 years), which makes the species prone to damage. In older phases, we found less damage compared with the other species and we thus conclude that Douglas-fir is predominantly exposed to risks in the first development stages (see Kaplan-Meier curve in Fig. 2).

Interestingly, the significant differences between coniferous and broadleaved species in the age-dependent survival models were largely evened out when displaying the probabilities over tree height. However, broadleaved species still had a higher survival probability then conifers up to a tree height of about $36 \mathrm{~m}$. Our findings therefore also have important implications for bio-economic studies, which seek to integrate survival probabilities into the comparison of economic risks and returns of different species or stand types. In order to be more realistic, different species' growth characteristics, not only age, but also height should be taken into account as a reference. Tree or stand ages are important information for economic models and management decisions that include adjustments of the rotation cycles under climate change (Staupendahl and Möhring 2011; Möllmann and Möhring 2017) and economic-based species selection (Neuner and Knoke 2017; Paul et al. 2019). To perform economic analyses, it is thus important to carry the variable tree or stand age in any study. However, it can be necessary to depict mortality probabilities as a function of tree or stand height, since these variables compensate for site and fertility differences and may be more causally linked to certain mortality agents than age (i.e., storm damage, snow breakage). Additionally, to refer to practical forest management it can also be necessary to show tree survival as a function of tree height or tree diameter, since many silvicultural regimes define harvestability based on these variables instead of rotation age. Here, our use of the term "risk" is limited to tree mortality. For comprehensive bio-economic analyses, the 
term "risk" needs to be broadened to represent the interplay of survival probabilities with tree growth, timber price fluctuations and harvesting costs (e.g., Möllmann and Möhring 2017; Neuner and Knoke 2017; Paul et al. 2019). Our findings may, however, offer important insights to improve the representation of survival probabilities in such bio-economic studies to inform management decisions in face of great uncertainty.

\section{Drivers of survival times}

The AFT models detected different mortality patterns among species with climatic, soil and silvicultural parameters as the most important drivers. The impact of climatic and silvicultural parameters is nearly equivalent, while soil parameters are less important (see Table 3). It is often stated in the literature that mostly climatic extremes drive irregular tree mortality (Bigler et al. 2006; Zimmermann et al. 2009; Neumann et al. 2017), like wind-throw under warmer winter temperatures or the reduced resistance of trees to pathogens under drought stress (Desprez-Loustau et al. 2006; Pretzsch et al. 2012; Allen et al. 2015).

Similar to other studies, we found maximum $\left(T_{\max }\right)$ and minimum $\left(T_{\min }\right)$ temperatures of the warmest and coldest month, respectively, influencing trees survival probabilities (Vanoni et al. 2016; Neumann et al. 2017; Brandl et al. 2020). Maximum temperature shortens the survival time of European beech, oak and Silver fir, which goes in line with other studies (Landmann and Dreyer 2006; Gärtner et al. 2008; Cailleret and Davi 2011; Schwarnweber et al. 2011; Mette et al. 2013; Nestola et al. 2018; Brandl et al. 2020). The influence became visible during the heatwave in summer 2003, in which the mortality of broadleaved species in the European forest monitoring network-level I sites increased from 0.2 to $0.5 \%$ year $^{-1}$, and to $1.2 \%$ year $^{-1}$ for coniferous species (Renaud and Nageleisen 2005). Although Norway spruce is known to be a drought-sensitive species, maximum temperature $\left(T_{\max }\right)$ and aridity $(\mathrm{Am})$ were not selected in its model. Part of the non-significant correlation can certainly be explained by the fact that Norway spruce suffers from warmer temperatures mostly in the lowlands (Hartl et al. 2014; Etzold et al. 2019), while many of the studied plots are located in the mountain regions. Another part of the nonsignificant correlation may result from the fact that bark beetle infestation could mask drought-caused death. Increasing summer temperatures accompanied by lower precipitation sums causes drought stress in Norway spruce stands, which in turn make Norway spruce more susceptible to bark beetle infestation (Temperli et al. 2013; Netherer et al. 2015). Further, increasing temperatures extend the growth and reproduction cycle of bark beetles, which in turn increases the risk of Norway spruce to be infested (Wermelinger and Seifert 1998). Further, the examined plots are all subjected to regularly and partially heavy thinning, which can modulate the impact of drought and heat (Gebhardt et al. 2012; Etzold et al. 2019).

In contrast, the Norway spruce model contained minimum temperature, maximum precipitation and their interaction as significant variables. In northern habitats, winter and spring temperatures have warmed faster than summer and fall temperatures (Vose et al. 2005), which might have a stronger influence on Norway spruce mortality. Winter precipitation accompanied by warmer temperatures leads to water-saturated soils, which causes tree's destabilization, especially when it coincidences with high winds (see review Mitchell 2013).

Contrastingly to Norway spruce, European beech seems to profit from warmer winter temperatures by showing an extended survival time. This goes in line with Brandl et al. (2020) and can be explained by the extension of the growing seasons and a lower risk of severe frost damages (Hofman et al. 2015).

Concerning water availability, our results suggest that wetter periods increase mortality of European beech, Norway spruce and Silver fir. Neumann et al. (2017) obtained similar results and related lower survival probability to the seasonal fluctuation. The vulnerability of beech to wetter conditions was also observed in a long-term study in Switzerland (Etzold et al. 2019) and may result from other cooccurring abiotic conditions. However, the impact of harsh weather conditions along with disturbances is influenced by the forest stand conditions (Seidl et al. 2011; Etold et al. 2019). Due to the low number of mixed stands in the permanent research plots, we could not analyze the influence of tree species admixture on survival probability as was done by Neuner et al. (2014). Rather, we demonstrated the shortterm destabilization effect of thinning (RelRemoval and RelDBHRemoval $>1$, see Table 3 ) on the tree survival times of the remaining trees. Thinning has been known to weaken the collective stand stability after the intervention most likely by disrupting the coherent canopy, making the stand particularly prone to wind-throw for several years following the thinning operation (Harrington and Reukema 1983; Gardiner et al. 2005; Nielsen 1995). Dodson et al. (2013) studied the effect of silvicultural practices in more detail by differentiating between initial tree sizes. The authors stated that trees with a smaller DBH seem to be more vulnerable after thinning than larger ones, while the risk to die also depended on the exact time of thinning prior to stochastic events like wind-throw (Hamilton 1986). Contrastingly, Ulvcrona et al. (2011) detected no influence of thinning on tree mortality at all.

However, we were not able to determine for how many years exactly the post-intervention temporary destabilization lasts, but other authors have reported between 2 and 8 years with high likelihoods around 5-6 years (Cremer et al. 
1982; Lohmander and Helles 1987; König 1995). A potential aspect that is not represented in this finding, however, is the long-term effect of thinning. Age is an inherent risk factor in AFT models, and this means that trees, which are favored by repeated thinning-based releases, will reach their target diameters at a much younger age than their un-thinned neighbors. Thus, they are exposed to the risk for a much shorter time. However, the vulnerability of a tree depends on the time and regularity of thinning and the reaction time of the remaining trees. It can thus not be concluded that thinning has a negative effect on stability in general. It rather has a temporary effect of destabilization in the years directly after a thinning but has been reported to have a stabilizing effect in the long term (Klein 1978; Cremer et al. 1982; Maccurrach 1991; Slodicák 1995; Müller 2002).

In this context, our findings of shortened survival times with increased basal area need interpretation: Since age and basal area of forest stands are positively correlated, this finding firstly indicates that in stands of the same age those stands with lower basal area are expected to have a higher survival time. Under this ceteris paribus view, thinned and more sparsely stocked stands are interpreted as advantageous. Secondly, however, there is an additional age penalty included in this finding: in a longitudinal view of one specific stand, the later developmental stages, which are naturally associated with higher stock and higher basal area, are more prone to shortened survival times. Both of these effects have to be considered when interpreting the impact of basal area on survival time.

Soil characteristics are often neglected in mortality studies. Even if soil characteristics change little from year to year, they can have a distinct continuous influence on tree mortality (Jim 1993) and can help to describe spatial patterns of varying mortality on different sites (Staupendahl and Zucchini 2011). Our findings indicate that higher base saturation, a measure of nutrient concentration in the soil, extends the survival time. On the other hand, it might increase the probability of tree mortality, due to both higher growth rates and fungi infestation rates (e.g., root rot), which in turn increases the propensity for natural disturbances such as wind-throw (Jim 1993; Stephenson et al. 2011; Griess et al. 2012). Another potential explanation of the inconsistent findings is that the analyzed causes of mortality are quite diverse and the physiological processes behind these causes require different soil predictors based on plot-specific information and/or even cause-specific survival models. Although soil properties are important to explain mortality patterns, we did not dispose of suitable predictors to detect such potential effects.

The finding that survival time of beech, fir and oak is extended for taller trees is counter-intuitive at first glance, since tree height is regularly found to be one of the most important risk factors for wind-throw and storm damage
(Hanewinkel et al. 2011). One explanation for this effect is the use of age as the variable for the abscissa. Since tree age and tree height are highly positively correlated, the mere depiction of tree survival over age already includes dimensional and thus height effects to a large degree. What we actually find in the detected coefficient values $<1$ for the height variables in our survival models (Table 3 ) is more the effect of the relative height of tree individuals within stands, either as height rank, or even in the absolute height term. It shows that taller individuals compared to shorter neighbors within a stand are more likely to survive longer. A second element to this finding is the cause-unspecific approach of the study: Wind-throw, snow and insect damage as well as unspecific salvage cuttings feature as events in our response variable but have different causal relations with tree height. For example, snow-damage occurs more frequently in younger and mid-aged Norway spruce stands with low taper (Valinger and Lundqvist 1992; Petty and Worrel 1981; Jalkanen and Mattila 2000; Nykänen et al. 1997; Päätalo 2000), while storm damage is known to be associated with very tall trees. Theses explanations underline our arguing that it is more appropriate to model tree mortality with cause-specific approaches when analyzing the climate change to mortality relation.

\section{Limitations of the study design}

The longevity of tree species and the often stochastic, rare and spatially varying mortality events make it difficult to model tree mortality. The presented approach of individual tree-based species-specific models allows the preservation of observed spatial, temporal or nested dependencies (Fox 2001) and base on an outstanding database in terms of observation length (1920-2014), sample size (2248 plots, 473,501 trees) and single measurements (2,100,016 observations). This enabled us to use time-dependent covariates. However, it should be kept in mind that the sampling design was originally established to assess tree growth under different environmental conditions and silvicultural treatments, whereas tree mortality records including specific mortality agents were only a byproduct. In combination with the lack of a grid-based, systematic sampling design, this aspect reduces the transferability of our findings in general and is a clear limitation of our study. Nevertheless, mortality agents are recorded since 1920, which is unique for Germany. However, mortality often results from multiple, interacting predisposing factors acting sometimes over a long period prior to the death event (Franklin and Harmon 1987; Bible 2001). Wind-throw could, for example, affect a tree that has been mechanically weakened by root or stem decay, fungi infestation or forked crowns. None of the mentioned information is provided in our data, making it difficult to classify a tree removal as an event or non-event according to the 
mortality agent. Questionable is further the determination of the precise time of death. Since the observation intervals are plurennial and differ in length, the precise death time is often not provided. Exceptions are made for undifferentiated salvage logged trees for which the forester recorded the date of death. In any case, we argue that potential inaccuracies due to uncertainty of the exact cause of removal are limited since our study focused on non-cause-specific modeling of disturbance-based mortality.

\section{Limitations in the statistical model approach}

Additionally to the limitations in the study design, there are also statistical restrictions. Model diagnostics are generally assessed by calculating the residuals (observed minus the predicted values in regression models). They are commonly graphed versus each explanatory variable implemented and not implemented in the model to check independence (Zuur et al. 2009). However, things are getting more complex with survival data due to the censored and/or truncated structure. Mills (2011) recommends calculating the Cox-Snell, Schoenfeld, Score and Martingale residuals to assess the overall model fit, to identify influential points and to evaluate the functional form of covariates. There are statistical methods to calculate the mentioned residuals for right-censored data, but to date, there are no methods for left-truncated and/or interval-censored data (Broström 2018).

To our knowledge, the present studies use for the first time individual tree information with time-varying covariates in survival models to detect the influence of climatic extremes and changing tree characteristics on mortality instead of using average values or categorical variables over the entire lifetime of a tree (Staupendahl 2011; Neuner et al. 2014; Neumann et al. 2017). There is only a limited amount of models, which can handle left-truncated and/or interval-censored data with time-varying covariates (Broström 2017). To date, it is not obvious how to consider timevarying covariates in model diagnostics (Broström 2018). Against this background, we assessed the model performance by comparing the modeled baseline with the observed Kaplan-Meier survival curve (see Fig. 6) and compared the model results based on the training data set (Table 3) with those determined with the test data set (see A1) (Campbell et al. 2010). The comparison between results obtained from the models of the training dataset and the test dataset shows that the magnitude and direction of the variables are similar (compare Table 3 and A1).

Furthermore, we know from clinical studies that subjects can experience mortality from more than one type of event and that those events can interact in delivering mortality (Moschberger et al. 2007). Ignoring such competing risks would lead to an overestimation of the modeled mortality rates. In terms of our study, it would lead to an overestimation of disturbance-based mortality. One could argue that removing trees by thinning operations compete with disturbance-based mortality, but thinning operations in our study were not performed systematically by favoring specific tree characteristics. Therefore, there was no need to consider planned thinning as a competing event and thinned trees were included as censored in our models.

In clinical studies, survival models are used to answer 'when' and 'why' an event happens. The underlying assumption is that all subjects have the same initial conditions before the treatment and that such conditions may change after its application. The length of the survival time is then measured from the initial stage to the event or the end of the study. In forest inventory data, the observation starts when the tree reaches a threshold-dbh. Therefore, the observation time does not correspond to a particular treatment that may affect the survival probability. Against this background, survival models based on inventory data often use stand age instead of observation time (Neuner and Knoke 2017; Nothdurft 2013; Brandl et al. 2020).

\section{Considerations for adapting forests to climate change}

Tree mortality is an important aspect in the discussions of how to adapt forests to climate change. Our study demonstrated that climate impact was inconsistent across species showing Norway spruce's survival probability reduced under warmer winter temperatures accompanied by wet periods, while European beech, oak and Silver fir suffer more from warmer summer temperatures. This effect was modulated by silvicultural measures (heavy thinning causing short-term destabilization effects) and soil parameters (increasing base saturation extended survival probabilities). In conclusion, the long-term data set of the experimental plots covering nearly a century of observations highlights the complex interaction regarding climate, silvicultural treatments and site characteristics. This information is of paramount importance when aiming at reducing economic losses or preserving forest ecosystem services.

Acknowledgements The authors acknowledge the support from the project SURVIVAL-KW funded by the Waldklimafonds of the German Federal Ministry of Food and Agriculture and the German Federal Ministry for the Environment, Nature Conservation and Nuclear Safety under Grant Number 28WC4088. Special acknowledgment goes to Elke Lenk who helped with her knowledge to understand the data structure. Further, we thank all the field workers who made the large data set possible and Thilo Wolf for providing the climate data set. All mentioned persons work for the Forest Research Institute Baden-Wuerttemberg.

Funding Open Access funding provided by Lib4RI - Library for the Research Institutes within the ETH Domain: Eawag, Empa, PSI \& WSL.

Open Access This article is licensed under a Creative Commons Attribution 4.0 International License, which permits use, sharing, adaptation, distribution and reproduction in any medium or format, as long 
as you give appropriate credit to the original author(s) and the source, provide a link to the Creative Commons licence, and indicate if changes were made. The images or other third party material in this article are included in the article's Creative Commons licence, unless indicated otherwise in a credit line to the material. If material is not included in the article's Creative Commons licence and your intended use is not permitted by statutory regulation or exceeds the permitted use, you will need to obtain permission directly from the copyright holder. To view a copy of this licence, visit http://creativecommons.org/licenses/by/4.0/.

\section{References}

Adame P, Del Río M, Cañellas I (2010) Modeling individual-tree mortality in Pyrenean oak (Quercus pyrenaica Willd.) stands. Ann For Sci 67:810. https://doi.org/10.1051/forest/2010046

Adams HD, Macalady AK, Breshears DD, Allen CD, Stephenson NL, Saleska SR, Huxman TE, McDowell NG (2010) Climate-induced tree mortality: earth system consequences. EOS Trans Am Geophys Union 91(17):153-154. https://doi. org/10.1029/2010EO170003

Albrecht AT, Kohnle U, Hanewinkel M, Bauhus J (2013) Storm damage of Douglas-fir unexpectedly high compared to Norway spruce. Ann For Sci 70:195-207. https://doi.org/10.1007/ s13595-012-0244-x

Allen CD, Macalady AK, Chenchouni H, Bachelet D, McDowell NG, Vennetier M et al (2015) On underestimation of global vulnerability to tree mortality and forest die-off from hotter drought in the Anthropocene. Ecosphere 6(8):1-55

Anderegg WRL, Kane JM, Anderegg LDL (2012) Consequences of widespread tree mortality triggered by drought and temperature stress. Nat Clim Change 3:30-36

Bauhus J, Forrester DI, Gardiner B, Jactel H, Vallejo R, Pretzsch H (2017) Ecological stability of mixed-species forests. Springer, Berlin, Heidelberg. https://doi.org/10.1007/978-3-662-54553-9

Bible KJ (2001) Long-term patterns of Douglas-fir and Western hemlick mortality in the Western Cascade Mountains of Washington and Oregon. Dissertation, University of Washington, Washington

Bigler C, Bräker OU, Bugmann H, Dobbertin M, Rigling A (2006) Drought as an inciting mortality factor in Scots Pine stands of the Valais, Switzerland. Ecosystems 9:330-343

Boeck A, Dieler J, Biber P, Pretzsch H, Ankerst DP (2014) Predicting tree mortality for European beech in Southern Germany using spatially explicit competition indicies. For Sci 60:613-622

Brandl S, Paul C, Knoke T, Falk W (2020) The influence of climate and management on survival probability for Germany's most important tree species. For Ecol Manag 458:117652. https://doi. org/10.1016/j.foreco.2019.117652

Bravo F, Montero G (2001) Site index estimation in Scot pine (Pinus sylvestris L.) stands in the high Ebro Basin (Northern Spain) using soil attributed. Forestry 74:395-406. https://doi. org/10.1093/forestry/74.4.395

Breshears DD, Cobb N, Rich PM, Price KP, Allen CD, Balice RG et al (2005) Regional vegetation die-off in response to global-changetype drought. Proc Natl Acad Sci USA 102:15144-15148

Broström G (2017). Event history analysis (Version 2.5.1) [eha-package]: R-CRAN Team

Broström G (2018) [email from 13.06.2018 regarding residuals in aftmodels using eha-package]

Burnham KP, Anderson D (2002) Model selection and multimodel inference. A practical information-theoretic approach. Springer, New York
Cailleret M, Davi H (2011) Effects of climate on diameter growth of co-occurring Fagus sylvatica and Abies alba an altitudinal gradient. Trees- Struct Funct 25:265-276

Campbell HE, Gray AM, Harris AL, Briggs AH, Taylor MA (2010) Estimation and external validation of a new prognostic model for predicting recurrence-free survival for early breast cancer patients in the UK. Br J Cancer 103:776-786

Cox DRSA (1995) Quick sign tests for trend in location and dispersion. Biometrika 42:80-95

Cremer KW, Borough CJ, McKinell FH, Carter PR (1982) Effects of stocking and thinning on wind damage in plantations. New Zeal J For Sci 12:244-268

Etzold S, Ziemińska K, Rohner B et al (2019) One century of forest monitoring data in Switzerland reveals species- and site-specific trends of climate-induced tree mortality. Front Plant Sci 10:307

Da Ronch F, Caudullo G, De Rigo D (2016) Pseudotsuga menziesii in Europe: distribution, habitat, usage and threats. In: San-MiguelAyanz D, Caudullo G, Houston Durrant T, Mauri A (eds) European Atlas of forest tree species. Publ. Off. EU, Luxembourg

Dănescu A, Albrecht AT, Bauhus J (2016) Structural diversity promotes productivity of mixed, uneven-aged forests in southwestern Germany. Oecologia 182:319-333

De Martonne E (1926) L'indice d'aridité. Bull. Ass. Geogr, De France, IX

Desprez-Loustau ML, Marçais B, Nageleisen L-M, Piou D, Vannini A (2006) Interactive effects of drought and pathogens in forest trees. Ann For Sci 63:597-612

Deutscher Wetterdienst (DWD) Climate Data Center (2018a) Grids of monthly averaged daily air temperature $(2 \mathrm{~m})$ over Germany

Deutscher Wetterdienst (DWD) Climate Data Center (2018b) Grids of monthly averaged daily maximum air temperature $(2 \mathrm{~m})$ over Germany

Deutscher Wetterdienst (DWD) Climate Data Center (2018c) Grids of monthly total precipitation over Germany

Deutscher Wetterdienst (DWD) Climate Data Center (2018d) Grids of monthly averaged daily minimum air temperature $(2 \mathrm{~m})$ over Germany

Dodson EK, Puettmann KJ, Ares A (2013) Thinning effects on tree mortality and snag recruitment in Western Oregon. Paper presented at the Proceedings of the density management workshop, Corvallis, Oregon

Dowle M, Srinivasan A, Gorecki J, Chirico M, Stetsenko P, Short T, ... Ritchie S (2019) R Package 'data. table'. Extension of 'data. frame

Eaton E, Caudullo G, Oliveira S, de Rigo D (2016) Quercus robur and Quercus petraea in Europe: distribution, habitat, usage and threats. In: San-Miguel-Ayanz J, de Rigo D, Caudullo G, Houston Durrant T, Mauri A (eds) European Atlas of forest tree species. Publ. Off. EU, Luxembourg, p e01c6df

Ehring A, Klädtke J, Yue C (1999) Ein interaktives Programm zur Erstellung von Bestandeshöhenkurven. Centralblatt für das gesamte Forstwesen 116:1-6

Eid T, Tuhus E (2001) Models for individual tree mortality in Norway. Forest Ecol Manag 154:69-84

Fernández CA (2008) Towards greater accuracy in individual-tree mortality regression. Master thesis, Michigan Technology University

Fortin M, Bédard S, DeBlois J, Meunier S (2008) Predicting individual tree mortality in northern hardwood stands under uneven-aged management in southern Québec, Canada. Ann For Sci $65: 1$

Fox JC (2001) Stochastic structure and individual-tree growth models. For Ecol Manag 154:261-276

Franklin JFS, Harmon ME (1987) Tree death: cause and consequence. Oxf J 37:550-556 
Fuhrer J, Beniston M, Fischlin A, Frei C, Goyette S, Jasper K, Pfister C (2006) Climate risks and their impact on agriculture and forests in Switzerland. Clim Change 70:79-102

Gardiner B, Marshall B, Achim A, Belcher RE, Wood CJ (2005) The stability of different silvicultural systems: a wind-tunnel investigation. Forestry 78:471-484

Gärtner S, Reif A, Xystrakis F, Sayer U, Bendagha N, Matzarakis A (2008) The drought tolerance limit of Fagus sylvatica forest on limestone in southwestern Germany. J Veg Sci 19:757-768

Gebhardt T, Grams T, Häberle K-H, Matyssek R, Schulz C, Grimmeisen W, Ammer C (2012) Helfen Durchforstungen bei Trockenheit? LWF aktuell 87:8-10

Geobasisdaten (2018) Az: 2851.9-1/19. From Landesamt für Geoinformation und Landentwicklung Baden-Wuerttemberg. http:// www.lgl-bw.de

Glomb P (2007) Statistische Modelle und Mehtoden in der Analyse von Lebenszeitdaten. Diplom thesis. University Oldenburg

Griess VC, Knoke T (2011) Growth performance, windthrow, and insects: meta-analyses of parameters influencing performance of mixed-species stands in boreal and northern temperate biomes. Can J For Res 41:1141-1159

Griess VC, Knoke T (2013) Bioeconomic modeling of mixed Norway spruce-European beech stands: economic consequences of considering ecological effects. Eur J For Res 132(3):551-552

Griess VC, Acevedo-Cabra R, Härtl F, Staupendahl K, Knoke T (2012) Does mixing tree species enhance stand resistance against natural hazards? A case study for spruce. For Ecol Manag 267:284-296

Hamilton DA (1986) A logistic model of mortality in thinned and unthinned mixed conifer stands of northern Idaho. For Sci 32:989-1000

Hanewinkel M, Hummel S, Albrecht A (2011) Assessing natural hazards in forestry for risk management: a review. Eur J For Res 130:329-351

Harrington CA, Reukema D (1983) Initial shock and long-term stand development following thinning in a Douglas-fir plantation. For Sci 29:33-46

Hartl C, Zang C, Dittmar C, Esper J, Göttlerin A, Rothe A (2014) Vulnerability of Norway spruce to climate change in mountain forests of the European Alps. Clim Res 60(2):119-132

Hartmann P, Buberl H, Puhlmann H, Schaefer J, Trefz-Malcher G, Zirlewagen D, von Wilpert K (2016) Waldböden Südwestdeutschlands - Ergebnisse der Bodenzustandserhebungen im Wald von 1989-1992 und 2006-2008. Verlag Kessel, Remagen-Oberwinter

Hennon PE, Dàmore DV, Schaberg PG, Wittwer DT, Shanley CS (2012) Shifting climate, altered niche, and a dynamic conservation strategy for Yellow-Cedar in the North Pacific Coastal Rainforest. Bioscience 62:147-158

Hosmer DW, Lemeshow S, May S (2008) Applied survival analysis: Regression modeling of time-to-event data, 2nd edn. WileyInterscience, Hoboken

Hülsmann L, Bugmann HKM, Commarmot B, Meyer P, Zimmermann S, Brang P (2016) Does one model fit all? Patterns of beech mortality in natural forests of three European regions. Ecol Appl 8:2465-2479

Jalkanen A, Mattila U (2000) Logistic regression models for wind and snow damage in northern Finland based on the National Forest Inventory data. For Ecol Manag 135:315-330

Jim CY (1993) Massive tree-planting failures due to multiple soil problems. Arboric J 17:309-331

Jutras S, Hökkä H, Alenius V, Salminen H (2003) Modeling mortality of individual trees in drained peatland site in Finland. Silva Fennica 37(235):251

Kane J, Kolb T (2014) Short- and long-term growth characteristics associated with tree mortality in southwestern mixed-conifer forests. Can J For Res 44:1227-1235
Kaplan EL, Meier P (1958) Non-parametric estimation from incomplete observation. J Am Stat Assoc 5:457-481

Klein M (1978) Der Einfluss verschiedener Behandlungen auf deren Massen- und Wertleistung sowie die Bestandessicherheit gegen Wind und Schnee. Dissertation, Universität Göttingen

König A (1995) Sturmgefährdung von Beständen im Altersklassenwald. Dissertation, TU München

Landmann G, Dreyer E (2006) Impacts of drought and heat on forest. Synthesis of available knowledge, with emphasis on the 2003 event in Europe. Ann For Sci 3:567-652

Lines ER, Coomes DA, Purves DW (2010) Influences of forest structure, climate and species composition on tree mortality across the eastern US. PLoS ONE 5:e13212

Lohmander P, Helles F (1987) Windthrow probability as a function of stand characteristics and shelter. Scand J For Res 2:227-238

Maccurrach RS (1991) Spacing: an option for reducing storm damage. Scott For 45:285-297

Mette T, Dolos K, Meinardus C, Bräuning A, Reineking B, Blaschke $\mathrm{M}$ et al (2013) Climatic turning point for beech and oak under climate change in Central Europe. Ecosphere 4:1-19

Mills M (2011) Introducing survival and event history analysis. SAGE Publications, London, New Deli, California

Mitchell SJ (2013) Wind as a natural disturbance agent in forests: a synthesis. Forestry 86:147-157

MLR-Ministerium für Ländlichen Raum und Verbraucherschutz Baden-Württemberg (1993) Hilfstabellen für die Forsteinrichtung - zusammengestellt für den Gebrauch in der Landesforstverwaltung. Stuttgart, $\mathrm{p} 188$

Möllmann TB, Möhring B (2017) A practical way to integrate in forest management decisions. Ann For Sci 74(4):63

Moore DF (2016) Applied survival analysis using R. Springer, Cham

Moschberger ML, Tordorff KP, Kochar N (2007) Review of Statistical Analyses for Competing Risks. Handb Stat 27:321-341

Müller F (2002) Modellierung von Sturm-, Schnee- und Rotfäulerisiko in Fichtenbeständen auf Einzelbaumebene. Dissertation, Technical University of Munich

Nestola E, Scartazza A, Di Baccio D, Castagna A, Ranieri A, Cammarano $\mathrm{M}$ et al (2018) Are optical indices good proxies for seasonal changes in carbon fluxes and stress-related physiological status in a beech forest? Sci Total Environ 612:1030-1041

Netherer S, Matthews B, Katzensteiner K, Blackwell E, Henschke P, Hietz P, Pennerstorfer J, Rosner S, Kikuta S, Schume H, Schopf A (2015) Do water-limiting conditions predispose Norway spruce to bark beetle attack? New Phytol 205:1128-1141

Neumann M, Mues V, Moreno A, Hasenauer H, Seidl R (2017) Climate variability drives recent tree mortality in Europe. Glob Change Biol 23:4788-4797

Neuner S, Knoke T (2017) Economic consequences of altered survival of mixed or pure Norway spruce under a drier and warmer climate. Clim Change 140:519-531

Neuner S, Albrecht AT, Cullmann D, Engels F, Griess VC, Hahn WA et al (2014) Survival of Norway spruce remains higher in mixed stands under dryer and warmer climate. Glob Change Biol 21:935-946

Nielsen CCN (1995) Recommendations for stabilisation of Norway spruce stands based on ecological surveys. In: Coutts J (ed) Wind and trees. University Press, Cambridge, pp 424-435

Nothdurft A (2013) Spatio-temporal prediction of tree mortality based on long-term sample plots, climate change scenarios and parametric frailty modeling. For Ecol Manag 291:43-54

Nykänen ML, Peltola H, Quine C, Kellomäki S, Broadgate M (1997) Factors affecting snow damage of trees with particular reference to European conditions. Silva Fennica 31:193-213

Päätalo ML (2000) Risk of snow damage in unmanaged and managed stands of scots pine, Norway spruce and birch. Scand J For Res 15:530-541 
Paul C, Brand S, Friedrich S, Falk W, Härtl F, Knoke T (2019) Climate change and mixed forests. How do altered survival probabilities impact economically desirable species proportions of Norway spruce and European beech. Ann For Sci 76(1):363

Petty JA, Worrel R (1981) Stability of coniferous tree stems in relation to damage by snow. Forestry $54: 115-128$

Pretzsch H, Schütz G, Uhl E (2012) Resistance of European tree species to drought stress in mixed versus pure forests: evidence of stress release by inter-specific facilitation. Plant Biol 15:483-495

Pulliam RH (2000) On the relationship between niche and distribution. Ecol Lett 3:349-361

Quantum GIS Development Team (2017) Quantum GIS geographic information system. http://qgis.osgeo.org

R Development Core Team (2014) R: language and environment for statistical computing. Vienna (Austria)

Renaud JP, Nageleisen LM (2005) Results from the European Network for damage monitoring. In: D. d. 1. s. d. forets (ed), Bilan de la santé des forets en 2004

Schelhaas MJ, Nabuurs GJ, Schuck A (2003) Natural disturbances in the European forests in the 19th and 20th centuries. Glob Change Biol 9:1620-1633

Schwarnweber T, Manthey M, Criegee C, Bauwe A, Schröder C, Wilmking M (2011) Drought matters - Declining precipitation influences growth of Fagus sylvatica L. and Quercus robur L in north-eastern Germany. For Ecol Manag 262:947-961

Seidl R, Fernandes PM, Fonseca TF, Gillet F, Jönsson AM, Merganicová K et al (2011) Modelling natural disturbances in forest ecosystems: a review. Ecol Mod 222:903-924

Seidl R, Thom D, Kautz M, Martin-Benito D, Peltoniemi M, Vacchiano $\mathrm{G}$ et al (2017) Forest disturbances under climate change. Nat Clim Change 7:395-402

Shannon CE, Weaver W (1949) The mathematical theory of communication. University of Illinois Press, Urbana

Sheil D, Burslem DFRP, Alder D (1995) The interpretation and misinterpretation of mortality rates measures. J Eco 83:331-333

Singer JD, Willett JB (2003) Applied longitudinal data analysis. University Press, Oxford

Slodicák M (1995) Thinning regime in stands of Norway spruce subjected to snow and wind damage. In: Coutts MP, Grace J (eds) Wind and trees. University Press, Cambridge, pp 436-447

Staupendahl K (2011) Modellierung der Überlebenswahrscheinlichkeit von Waldbeständen mithilfe der neu parametrisierten WeibullFunktion. [Modellingthe survival probability of forest stands using the parameterised Weibull function]. Forstarchiv 82:10-19

Staupendahl K, Möhring B (2011) Integrating natural risk into silvicultural decision models: a survival function approach. For Policy Econ 13(6):496-502

Staupendahl K, Zucchini W (2011) Schätzung von Überlebensfunktionen der Hauptbaumarten auf der Basis von Zeitreihendaten der Rheinland-Pfälzischen Waldzustandserhebung. Allg. Forstu.J.-Ztg. 128(7/8):129-145
Stephenson NL, van Mantgem PJ, Bunn AG (2011) Causes and implications of the correlation between forest productivity and tree mortality rates. Ecol Monogr 81:2712-2724

Temperli C, Bugmann H, Elkin C (2013) Cross-scale interactions among bark beetles, climate change and wind disturbances: a landscape modeling approach. Ecol Monogr 83:383-402

Thapa R, Burkhart HE (2015) Modeling stand-level mortality of loblolly pine (Pinus taeda L.) using stand, climate, and soil variables. For Sci 61:834-846

Therneau T (2018) Survival analysis (Version 2.42-6): CRAN R Development Team

Ulvcrona KA, Kiljunen N, Nilsson U, Ulvcrona T (2011) Tree mortality in Pinus sylvestris stands in Sweden after pre-commercial thinning at different densities and thinning height. Scand J For Res 26:319-328

Valinger E, Lundqvist L (1992) The influence of thinning and nitrogen fertilisation on the frequency of snow and wind induced stand damage in forests. Scott For 46:311-320

Vanoni M, Bugmann H, Nötzli M, Bigler C (2016) Drought and frost contribute to abrupt growth decreases before tree mortality in nine temperate tree species. For Ecol Manag 382:51-63

Vose RS, Easterling DR, Gleason B (2005) Maximum and minimum temperature trends for the globe: an update through 2004. Geophys Res Lett. https://doi.org/10.1029/2005GL024379

Wermelinger B, Seifert M (1998) Analysis of the temperature dependent development of the spruce bark beetle Ips typographus (L.) (Col., Scolytidae). J Appl Entomol 122:185-191

Wickham H, Francois R, Henry L, Müller K (2018) A grammar of data manipulation: CRAN

Wykoff WR, Crookston NL, Stage AR (1982) User's guide to the stand prognosis model. United States Department of Agriculture- Forest Service- Intermountain Forest and Range Experiment Station, Ogden

Zhang Z (2016) Parametric regression model for survival data: Weibull regression model as an example. Ann Transl Med 4(24):484

Zimmermann NE, Yoccoz N, Edwards TCJ, Meier ES, Thuiller W, Guisan A et al (2009) Climatic extremes improve predictions of spatial patterns of tree species. PNAS 106:19723-19728

Zuur AF, Ieno EN, Walker NJ, Saveliev AA, Smith GM (2009) Mixed effects models and extensions in ecology with R. Springer Science \& Usiness Media, New York

Zuur AF, Ieno EI, Elphick CS (2010) A protocol for data exploration to avoid common statistical problems. Methods Ecol Evol 1:3-14

Publisher's Note Springer Nature remains neutral with regard to jurisdictional claims in published maps and institutional affiliations. 